\title{
PENDEKATAN PRA (PARTICIPATORY RESEARCH APPRAISAL) DALAM PENGEMBANGAN KOPI ARABIKA SPECIALTY KETINGGIAN SEDANG BERBASIS KAWASAN DI KABUPATEN JEMBER
}

\section{APPROACH OF PRA (PARTICIPATORY RESEARCH APPRAISAL) IN DEVELOPMENT OF SPECIALTY AREA BASED ARABIC COFFEE JEMBER DISTRICT OF JEMBER}

\author{
Diah Puspaningrum $^{1}$, dan Titin Agustina ${ }^{1}$ \\ Program Studi Agribisnis Fakultas Pertanian Universitas Jember \\ e-mail: puspafauzan38@gmail.com
}

\begin{abstract}
ABSTRAK
Kopi Arabika yang berada di Kabupaten Jember ini diharapkan dapat menjadi kopi arabika specialty ketinggian sedang dan berbasis kawasan karena hanya bisa ditanam di ketinggian lebih dari $700 \mathrm{dpl}$. Metode penelitian menggunakan pendekatan kualitatif sedangkan penentuan daerah penelitian secara purposive method. Tujuan utama dari pelatihan pengolahan primer dan pengolahan sekunder yang diberikan kepada petani adalah untuk memberikan nilai tambah (added value) kepada komoditas kopi terutama kopi arabika ketinggian sedang di Kabupaten Jember.Berdasarkan hasil uji testcup, final score kopi arabika ketinggian sedang dari Lembaga Masyarakat Desa Hutan Taman Putri Desa Kemiri Kecamatan Panti adalah sebesar 60.50. Hasil dari uji testcup kopi arabika di Desa Karangpring Kecamatan Sukorambi Kabupaten Jember adalah sebesar 78.50.Dapat disimpulkan bahwa kopi arabika di Kabupaten Jember sangat berpotensi untuk mendapatkan kualitas specialty asalkan memenuhi persyaratan bahan baku dan diolah secara basah dengan SOP dari Puslitkoka. Berdasarkan kegiatan monitoring dan evaluasi bahwa kegiatan penelitian dengan menggunakan PRA (Participatory Research Appraisal)dalam pengembangan kopi arabika specialty ketinggian sedang berbasis kawasan di Kabupaten Jember memerlukan upaya yang terus-menerus dengan melibatkan partisipasi aktif masyarakat desa hutan yang benarbenar-benar ingin melakukan perubahan dalam menjawab kebutuhan utamanya untuk meningkatkan pendapatannya serta dukungan dari berbagai pihak yang secara sinergis untuk mendukung aktifitas dalam melakukan pengolahan primer maupun pengolahan sekunder.
\end{abstract}

Kata kunci: Kopi Arabika, PRA, Kabupaten Jember

\section{ABSTRACT}

Arabica coffee located in Jember Regency is expected to become arabica coffee is a specialty of medium height and region-based because it can only be planted at an altitude of more than $700 \mathrm{dpl}$. The research method used a qualitative approach while determining the research area by purposive method. The main objective of the primary and secondary processing training given to the farmers is to provide added value to the coffee commodities, especially the mediumheight arabica coffee in Jember District. Based on the testcup test result, the final score of arabica coffee of medium height from Lembaga Taman Desa Taman Putri Desa Kemiri Kecamatan Panti is 60.50. The results of arabica coffee testcup test in Karangpring Village Sukorambi District Jember Regency is 78.50. It can be concluded that arabica coffee in Jember Regency has the potential to get a specialty quality as long as it meets the requirements of raw materials and processed in wet with SOP from Puslitkoka. Based on monitoring and evaluation activities that research activities using PRA (Participatory Research Appraisal) in the development of arabica specialty of mediumelevated specialty in Jember District requires a continuous effort by involving active participation of forest villagers who really want to make changes in answering its main need to increase its revenue and support from various parties that synergistically to support the activity in performing primary processing and secondary processing.

Key Word : Arabica Coffee, PRA, Jember Distric 


\section{PENDAHULUAN}

Desa Kemiri dan Desa Karangpring merupakan desa yang berada pada ketinggian 600 meter diatas permukaan laut, dengan curah hujan $500 \mathrm{~mm} / \mathrm{th}$. Sehingga desa ini cocok untuk tanaman perkebunan. Salah satunya adalah komoditas kopi. Saat ini yang dibudidayakan sebagian besar adalah jenis robusta, tetapi mulai tiga tahun yang lalu di Desa Kemiri dan Desa Karangpring terutama yang berada di ketinggian diatas $600 \mathrm{dpl}$ telah dibudidayakan jenis kopi arabika. Arabica dan Robusta adalah dua spesies kopi yang berbeda. Perbedaan umum terletak pada rasa, kondisi di mana dua spesies itu tumbuh, dan perbedaan ekonomis. Soal rasa, Arabica memiliki variasi rasa yang lebih beragam, dari rasa manis dan lembut hingga rasa kuat dan tajam. Sebelum disangrai, aromanya seperti blueberry, setelah disangrai, biji kopi Arabica beraroma buah-buahan dan manis, sedangkan Robusta memiliki variasi rasa netral sampai tajam dan sering dianggap memiliki rasa seperti gandum. Biji kopi robusta sebelum disangrai beraroma kacangkacangan. Sayangnya jarang terdapat robusta berkualitas tinggi di pasaran. Selain perbedaan harga biji kopi Arabica yang lebih tinggi dibandingkan dengan harga biji kopi Robusta.

Dengan adanya perbedaan dalam hal rasa dan terutama adanya perbedaan harga antara kopi robusta dan arabika, sebagian petani kopi di Kabupaten Jember mencoba membudidayakan kopi Arabica variaetas Sigararutan dan Lini S975 yang benihnya berasal dari Pusat Penelitian Kopi dan Kakao (Puslitkoka).

Salah satu yang menyebabkan petani kopi mau beralih untuk menanam kopi arabika adalah adanya ketidakpastian harga dari kopi robusta. Berdasarkan latar belakang tersebut diatas maka untuk mencapai pengembangan kopi arabika specialty ketinggian sedang berbasis kawasan di Kabupaten Jember perlu dilakukan capacity buildingterhadap kelembagaan shareholderdengan melakukan rekayasa sosial, ekonomi, teknologi dan nilai tambah.

\section{METODOLOGI PENELITIAN}

\section{Penentuan Daerah Penelitian}

Metode penentuan daerah penelitian adalah secara sengaja (Purposive Method) yaitu terdiri dari 2 Kecamatan di Kabupaten Jember yang membudidayakan kopi arabika yaitu Desa Karangpring Kecamatan Sukorambi dan Desa Kemiri Kecamatan Panti. Pemilihan kedua desa tersebut karena ada konversi budidaya kopi robusta menjadi kopi arabika ketinggian sedang yang akan panen pertamakali pada bulan Mei 2013. Panen perdana diperkirakan sebesar 70 ton. Diharapkan pada tahun 2015 terdapat 2000 Ha kopi Arabika dengan perkembangan 500 Ha per tahun.

\section{Metode Penelitian}

Metode yang digunakan dalam penelitian ini adalah Action research dengan participatory research Appraisal (PRA) yaitu pelaksanaan kegiatan penelitian dimana kegiatan penelitian dilakukan mulai menyusun desain, instrument, pengumpulan data, pengolahan, analisis data sampai menyusun laporan selalu bersama masyarakat yang diperankan bukan sebagai obyek tetapi serbagai subyek (Adimihardja, 2003). PRA dilakukan dalam rangka rekayasa sosial, ekonomi, teknologi dan nilai tambah dari kopi arabika specialty ketinggian sedang di Kabupaten Jember.

\section{Metode Pengambilan Sampel}

PendekatanPRA menggunakan sampel betujuan (purposive sampling) dalam melakukan rekayasa sosial, ekonomi, teknologi dan nilai tambah ditujuan kepada lembaga masyarakat desa hutan yang membudidayakan kopi Arabika Specialty ketinggian sedang di Kabupaten Jember. Untuk saat ini hanya masih ada dua Lembaga Masyarakat Desa Hutan (LMDH) yaitu LMDH Taman Putri di Desa Kemiri Kecamatan Panti dan LMDH Sumber 
Kembang di Kecamatan Karangpring
Kabupaten

Metode Pengumpulan Data dan Analisis Data dalam PRA

\section{Metode dan Langkah-Langkah}

Metode dan langkah-langkah yang ditempuh, terutama dalam pengumpulan dan analisis data mengikuti metode-metode yang lazim dimanfaatkan dalam $R R A$ dan $P R A$ (Chambers 1996: 36-39), antara lain:

1) Pengumpulan sumber sekunder, berupa berkas, laporan, peta, foto, artikel, buku, catatan resmi;

2) Mewawancarai informan kunci, untuk mengetahui secara mendalam mengenai persoalan dan masalah dalam masyarakat;

3) Melakukan wawancara semi-terstruktur, memperoleh checklist yang terbuka dan, mungkin, unpredictable;

4) Melakukan pertemuan dan wawancara dengan kelompok dan jenis serta kepentingan;

5) Membuat model dan peta secara partisipatif, bersama masyarakat terkait dengan pendidikan dan pelatihan budidaya kopi arabika.

6) Membuat diagram secara partisipatif: metode untuk identifikasi kelompok dan lembaga penting di dalam dan bagi komunitas, serta hubungan mereka;

7) Estimasi dan kuantifikasi, dapat menggunakan ukuran lokal dalam keberhasilan pendidikan dan pelatihan

8) Analisis dan penyajian: peta, model, diagram, penemuan yang disajikan oleh warga atau warga bersama peneliti, yang diuji, dikoreksi dan didiskusikan;

9) Perencanaan partisipatif, pembuatan anggaran dan pemantauan: warga menyiapkan rencana (jika mungkin sampai pada anggaran, jadual dan pemantauan perkembangannya);

10) Kuesioner sederhana pada akhir proses, dirancang untuk pengisian tabel untuk laporan atau yang akan dibutuhkan kemudian;
11) Laporan tertulis oleh fasilitator dan/atau bersama warga, segera setelah kegiatan atau $P R A$.

\section{HASIL DAN PEMBAHASAN}

\section{Penyusunan Model Partisipatif bersama} Masyarakat Desa Hutan

Pengumpulan data dan analisis data dalam Participatory Research Appraisal untuk pengembangan kopi arabika specialty ketinggian sedang berbasis kawasan di Kabupaten Jember mengikuti metodemetode yang lazim dimanfaatkan dalam Participatory Research Appraisal (Chambers 1996). Metode yang dilakukan yaitu:

1) Melakukan pengumpulan data baik primer maupun sekunder. Data tersebut diantaranya sudah diperoleh meliputi kajian sosial dan ekonomi dalam pengembangan kopi arabika specialty ketinggian sedang berbasis kawasan di Kabupaten Jember.

2) Dilakukan wawancara dengan informan kunci terkait kopi arabika di Desa Kemiri Kecamatan Panti dan Desa Karangpring Kecamatan Sukorambi. Informan kunci antara lain adalah dari Pusat Penelitian Kopi dan Kakao, Penyuluh Pertanian Lapangan dari Dinas Perkebunan dan Kehutanan Kabupaten Jember, Perum Perhutani KPH Jember, serta para Ketua Lembaga Masyarakat Desa Hutan yaitu LMDH Taman Putri dan LMDH Sumber Kembang.

3) Pertemuan dan wawancara dengan kelompok dan jenis kepentingan dilakukan dengan Focus Group Discussion (FGD). Dari hasil FGD tersebut dapat dibuat model secara partisipatif antara stakeholder dan shareholder dalam pengembangan Kopi arabika specialty berketinggian sedang berbasis kawasan di Kabupaten Jember. Dimana baik shareholder maupun stakeholder menghendaki dilakukan peningkatan kapasitas kelembagaan 
(capacity building) untuk Lembaga Masyarakat Desa Hutan maupun Koperasi Masyarakat Desa Hutan (KMDH). Capacity Building dilakukan dengan memberikan pelatihan pengolahan primer (dari asalan ke HS atau dari pengolahan kering ke pengolahan basah) dan pengolahan sekunder yaitu dari ose (berasal dari pengolahan basah/HS) menjadi kopi bubuk. Selama ini petani kopi sebagian besar (lebih dari 50\%) masih melakukan pengolahan kering dan tidak semua petani mau melakukan petik merah. Padahal agar diperoleh citarasa specialty harus $90 \%$ petik merah. Sehingga dibutuhkan sosialiasi dan pemahaman kepada petani akan pentingnya petik merah dalam pengolahan basah. Pengolahan kopi primer (pengolahan basah) dapat meningkatkan kualitas kopi sehingga harga jual juga menjadi lebih tinggi daripada dilakukan pengolahan kering.

4) Membuat Model dan Peta secara partisipatif bersama masyarakat terkait dengan pengembangan kopi arabika specialty berketinggian sedang termasuk melakukan identifikasi kelompok dan lembaga yang penting (stakeholder) terhadap shareholder (Lembaga Masyarakat Desa Hutan).

Tabel 1. Peta Partisipatif Shareholder dan Stakeholder dalam Pengembangan Kopi AabikaSpecialty Ketinggian Sedang Berbasis Kawasan di Kabupaten Jember

\begin{tabular}{|c|c|c|}
\hline No & $\begin{array}{c}\text { Nama } \\
\text { Lembaga }\end{array}$ & alty \\
\hline 1. & $\begin{array}{l}\text { Lembaga } \\
\text { Masyarakat } \\
\text { Desa Hutan } \\
\text { Taman Putri dan } \\
\text { Sumber } \\
\text { Kembang }\end{array}$ & $\begin{array}{l}\text { - Perlu dilakukan komunikasi yang lebih intensif antara Lembaga } \\
\text { Masyarakat Desa Hutan dan Perum Perhutani Jember dalam } \\
\text { kerangka PHBM. Sehingga kerjasama dan kemitraan antara Perum } \\
\text { Perhutani dan LMDH bisa berkelanjutan. } \\
\text { - Hutan relative aman dari penjarahan hanya perlu ditingkatkan } \\
\text { kemandirian LMDH dengan membangun Unit Produksi untuk } \\
\text { meningkatkan kesejahteraan petani }\end{array}$ \\
\hline 2. & $\begin{array}{l}\text { Koperasi } \\
\text { Masyarakat } \\
\text { Desa Hutan } \\
\text { Putri Jaya dan } \\
\text { Kembang Jaya }\end{array}$ & $\begin{array}{l}\text { - Peningkatan kapasitas koperasi perlu dilakukan dengan } \\
\text { meningkatkan modal sendiri yang berasal dari simpanan pokok dan } \\
\text { simpanan wajib. Karena selama ini simpanan pokok dan simpanan } \\
\text { wajib belum berjalan, yang sudah berjalan selama ini anggota hanya } \\
\text { meminjam. Modal KMDH berasal dari hibah Dinas Koperasi dan } \\
\text { UMKM Jawa Timur sebesar } 25 \text { juta. } \\
\text { - Koperasi dapat membantu permodalan petani dalam budidaya kopi } \\
\text { arabika serta peminjaman pupuk } \\
\text { - Perlu dilakukan pertemuan secara rutin agar simpan pinjam dapat } \\
\text { berjalan dengan baik. Pertemuan maksimal dilakukan } 3 \text { bulan } \\
\text { sekali. } \\
\text { - Pembayaran simpanan wajib dapat dilakukan pada saat panen kopi. } \\
\text { - Peminjaman seharusnya disesuaikan dengan simpanan wajib yang } \\
\text { dimiliki oleh anggota } \\
\text { - Yang penting koperasi harus melakukan RAT dahulu sehingga } \\
\text { kredibilitas lembaga sudah teruji } \\
\text { - RAT dapat digunakan sebagai syarat dalam memperoleh }\end{array}$ \\
\hline
\end{tabular}


permodalan dari perbankan

- Harus memberikan manfaat kepada anggota sehingga terdapat ikatan antara koperasi dan anggota serta dapat menarik non anggota untuk menjadi anggota koperasi

3. Universitas

- Menekankan posisi Universitas Jember hanya sebagai "pengantar" Jember dalam artian memfasilitasi, memediasi masyarakat desa hutan untuk mengembangkan kapasitasnya dalam pengembangan kopi arabika. Tetapi semuanya tergantung dari kemauan dan motivasi dari lembaga masyarakat desa hutan sendiri apakah mau menguatkan lembaganya (peningkatan kapasitas lembaga) yang pada gilirannya akan meningkatkan kesejahteraannya atau hanya cukup seperti ini saja. Stakeholder tidak akan memiliki energy yang begitu besar untuk mendorong kemajuan lembaga tanpa adanya kemauan dari internal lembaga sendiri.

- Universitas Jember adalah gudangnya ilmu dan teknologi yang terbuka untuk masyarakat desa hutan apabila mereka menghendaki.

- Universitas Jember memiliki community development dengan komoditas unggulan kopi sehingga dapat membantu melakukan pembinaan kepada petani kopi

- Untuk memberikan fasilitasi dan pembinaan tersebut Universitas Jember akan mengadakan pelatihan pengolahan basah (Primer) sampai menjadi kopi bubuk (pengolahan sekunder)

- Apabila sudah menjadi kopi bubuk, nilai tambah komoditas kopi bisa dinikmati oleh masyarakat desa hutan, tidak dinikmati oleh tengkulak dan pengusaha

\begin{tabular}{lll}
\hline No & $\begin{array}{l}\text { Nama } \\
\text { Lembaga }\end{array}$ & Peran dalam Pengembangan Kopi Arabika Specialty \\
\hline 3. $\begin{array}{l}\text { Dinas } \\
\text { Perkebunan dan } \\
\text { Kehutanan }\end{array}$ & $\begin{array}{l}\text { Walaupun secara kelembagaan perhatian kepada Lembaga } \\
\text { Kabupaten }\end{array}$ \\
Jember & $\begin{array}{l}\text { Masyarakat Desa belum dilakukan secara baik karena ada } \\
\text { bukan pemerintah Daerah. Tetapi ada komitmen dari PPL bahwa } \\
\end{array}$ \\
& akan dilakukan pendampingan kepada masyarakat desa hutan \\
& terutama dalam pengembangan kopi arabika. \\
& Sudah memberikan bantuan alat pengolah primer dan sekunder \\
& yaitu washer, pulper, grinder, roaster, dan powder kepada \\
& kelompok tani yang melakukan usahatani kopi. \\
& Perlu ketelatenan dan kesabaran dalam mendampingi masyarakat \\
& (proses pemberdayaan) sehingga tujuan kesejateraan masyarakat \\
& bisa tercapai. \\
& Pemasaran kopi bisa dilakukan dalam Hari Perkebunan di Jawa \\
& Timur yang akan diselenggarakan bulan September di Kabupaten \\
& Jember. Sehingga produk LMDH yaitu kopi bubuk akan bisa \\
& dipromosikan
\end{tabular}

4. Perum Perhutani - LMDH harus mendorong KMDH untuk menjadi mandiri dengan KPH Jember memiliki unit usaha produktif diantaranya adalah dengan 
memproduksi kopi bubuk

- Permodalan dapat diperoleh dari berbagai sumber dana yaitu diantaranya adalah Program Corporate Social Responsibility (CSR) dan Bina Lingkungan dan Usaha dari Perum Perhutani asalkan tidak lagi memiliki tanggungan.

- Syarat memperoleh dana dari Bina Lingkungan dan Usaha yaitu dengan mengajukan proposal pendanaan usaha serta memiliki agunan berupa sertifikat.

- Dana bisa dicairkan sebesar $60 \%$ dari total nilai agunan

- Diperlukan sketsa anggota LMDH sehingga mengetahui hasil produksi tiap tiap anggota dan dibuat profil sehingga bisa mengetahui pola tanam kedepan dan juga rencana pemasarannya

- Untuk Pemasaran kopi bubuk arabika Perum Perhutani bersedia membantu promosi dengan menjual di outlet hasil produksi LMDH Perum Perhutani di Jubung, di Koperasi Karyawan Perum Perhutani maupun secara direct sales dengan menawarkan secara langsung serta apabila ada gelar produk/pameran untuk hasil-hasil produk LMDH

5. Pusat Penelitian - Banyak melakukan pendampingan mulai dari hulu (teknologi Kopi dan Kakao budidaya kopi arabika, memberikan bibit kopi arabika yang paling sesuai untuk ketinggian sedang yaitu dibawah $1000 \mathrm{dpl}$ ) serta hilir yaitu pengolahan kopi baik primer (olah basah) maupun secara sekunder (kopi bubuk)

- Produksi kopi arabika dari LMDH sudah diikutsertakan pameran di Paris.

- Sudah memberikan Standart Operational Procedure (SOP) pengolahan kopi primer dan sekunder

- Telah ada prototype kopi bubuk kopi arabika yang telah diuji citarasanya ternyata telah masuk grade specialty tetapi belum ada sertifikat secara legal

- Untuk pengemasan kopi bubuk Puslit Koka bersedia membantu memfasilitasi LMDH

6. Koperasi Petani - Melakukan pembibitan kopi arabika. Dengan target sebanyak 500 Kopi Indokom Ha/tahun.

- Memberikan bantuan permodalan kepada petani kopi

- Telah Memiliki alat powder dan sealer untuk pengolahan kopi bubuk hanya saja belum ada pengalaman dan tidak tahu strategi bisnis untuk kopi bubuk disamping kompetisi pasar kopi bubuk yang sangat besar. Terutama pabrikan besar seperti Kapal api dan Wings food (Top coffee)

- Siap membeli hasil produksi berapapun untuk arabika karena belum dapat memenuhi permintaan pasar asalkan kualitas sesuai dengan permintaan eksportir (olah basah dan petik merah) 
5) Membuat diagram secara partisipatif untuk pengembangan kopi arabika specialty ketinggian sedang berbasis kawasan di Kabupaten Jember

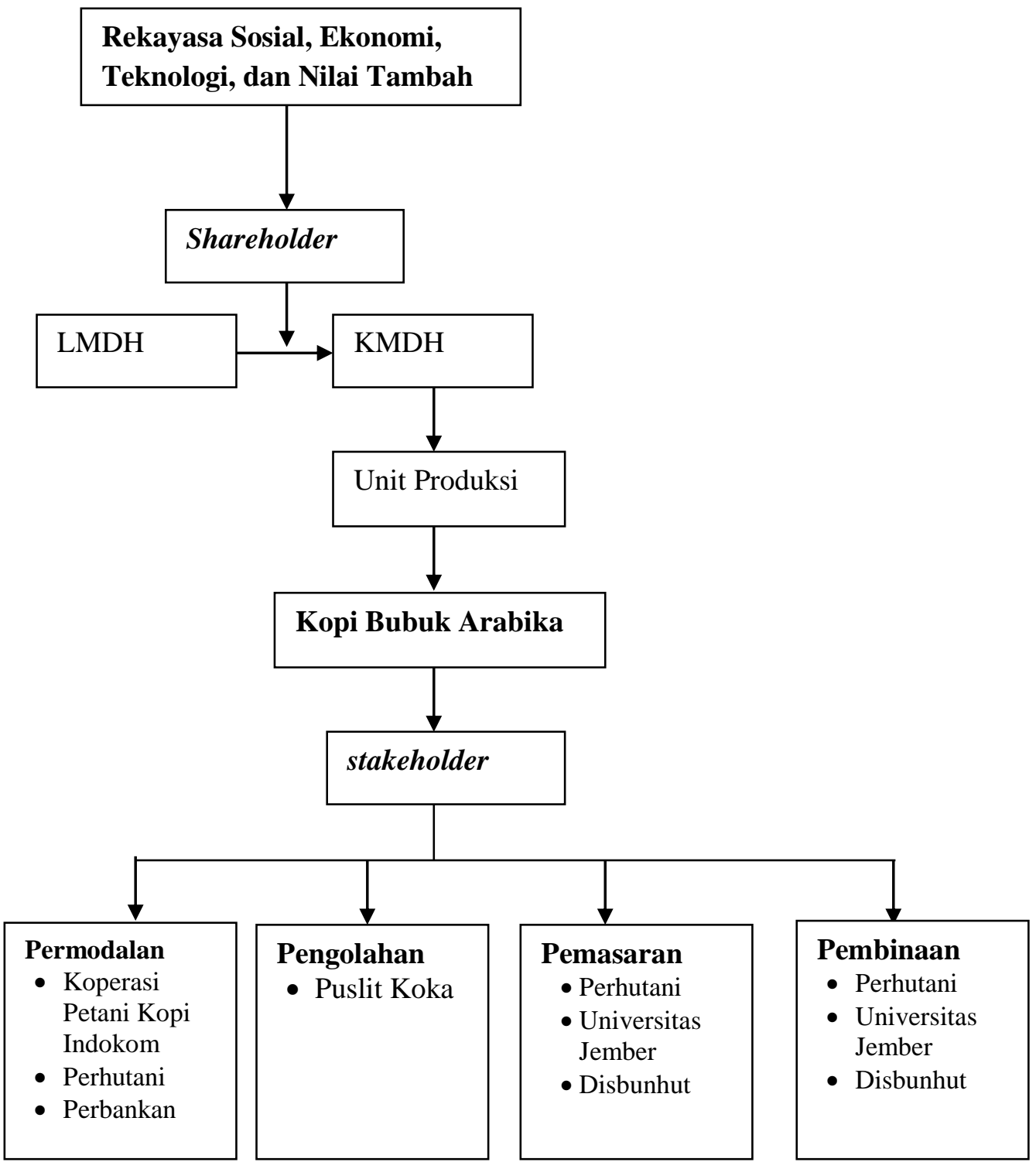

Gambar 1. Diagram Partisipatif Pengembangan Kopi Arabika Specialty Ketinggian

Sedang Berbasis Kawasan diKabupaten Jember

6) Menentukan perencanaan, estimasi dan kuantifikasi dalam keberhasilan pengembangan kopi arabika specialty ketinggian sedang berbasis Kawasan di Kabupaten Jember beserta jadwal dan pemantauan perkembangannya. Dari hasil FGD keberhasilan pengembangan kopi arabika specialty sangat tergantung pada motivasi dari shareholder dalam melakukan pengolahan primer (olah basah) dan olah sekunder (kopi bubuk) serta peran dari stakeholder dalam melakukan rekayasa baik sosial, ekonomi, teknologi dan nilai tambah terhadap kopi arabika. Adapun secara partisipatif maka perencanaan, estimasi dan kuantifikasi keberhasilan dalam pengembangan kopi arabika melalui berbagai rekayasa itu adalah sebagai berikut: 
Tabel 2. Perencanaan Partisipatif berserta estimasi dan Keberhasilan Pengembangan Kopi

Arabika Specialty Ketinggian Sedang Berbasis Kawasan di Kabupaten Jember

\begin{tabular}{ll}
\hline No & Rencana Kegiatan \\
\hline 1. & Rekayasa Sosial \\
& Capacity building \\
& terhadap pengurus \\
& dan anggota dari \\
& LMDH dan KMDH
\end{tabular}

2. Rekayasa Ekonomi

Peningkatan akses terhadap permodalan dengan mengajukan proposal untuk mendapatkan dana CSR dan Bina Lingkungan dan Usaha dari Perum Perhutani

3. Rekayasa Teknologi Pelatihan pengolahan kopi primer (olah basah) dan pengolahan sekunder (kopi bubuk) kepada pengurus dan anggota LMDH dan $\mathrm{KMDH}$

4. Rekayasa

Tambah

Memproduksi kopi

bubuk dan

pengemasan kopi bubuk arabika sekaligus pembuatan desain kemasan yang menarik

\section{Mendapatkan}

pendampingan

dalam pembuatan

proposal terutama

dalam business

plan dan efisiensi

usaha produksi

kopi bubuk
Target Keberhasilan

a.Bertambahnya

pengetahuan mengenai

organisasi koperasi bagi

anggota LMDH

b.Peningkatan kualitas sumberdaya pengurus

dalam pembukuan serta administrasi organisasi

Mendapatkan bantuan dana lunak untuk unit usaha KMDH dalam produksi kopi bubuk arabika

arika
Stakeholder

Universitas

Jember

Universitas

Jember

Perhutani

Koperasi

Petani Kopi

Indokom

\author{
Puslitkoka \\ Universitas \\ Jember
}

kopi bubuk dari ose kopi HS (olah basah) sehingga kualitas bisa menembus segmen menengah keatas
a.Mampu melakukan pengemasan dengan desain menarik dan memasarkan baik secara direct maupun non direct (membuat website)
b.Mengikuti Gelar Produk Perkebunan pada bulan September dari Disbunhut Kabupaten Jember
c. memperoleh sertifikasi citarasa specialty dari Puslitkoka (taste coffee)

\author{
Perhutani \\ Disbunhut \\ Kabupaten \\ Jember \\ Universitas \\ Jember
}


7) Melakukan Monitoring dan Evaluasi serta pelaporan dari hasil kegiatan rekayasa untuk pengembangan kopi arabika specialty ketinggian sedang berbasis kawasan di Kabupaten Jember. Kegiatan Monitoring dan Evaluasi dapat dilakukan setelah kegiatan rekayasa sosial, ekonomi, teknologi dan nilai tambah telah dilaksanakan. Setelah itu dilakukan evaluasi dan pelaporan dari hasil kegiatan Participatory Research Appraisal (PRA) untuk pengembangan kopi arabika specialty ketinggian sedang berbasis kawasan di Kabupaten Jember.

\section{Pelaksanaan Kegiatan Partisipatif Pengembangan Kopi Arabika Specialty Ketinggian Sedang Berbasis Kawasan di Kabupaten Jember}

\section{Rekayasa Sosial}

Rekayasa sosial terhadap pengurus dan anggota Lembaga Masyarakat Desa Hutan dimaksudkan untuk meningkatkan kapasitas pengurus dan anggota Lembaga Masyarakat Desa Hutan Taman Putri dan Lembaga Masyarakat Desa Hutan Sumber Kembang dalam pengembangan kopi arabika specialty ketinggian sedang di Kabupaten Jember.Pemasaran kopi arabika sebenarnya lebih baik dijual setelah diberikan nilai tambah atau diolah dulu daripada dijual dalam bentuk gelondong. Apalagi saat ini konsumen kopi beragam mulai dari segmen yang paling rendah (warung kopi) hingga segmen yang tinggi (cafe-cafe maupun starbuck). Secangkir kopi bisa berharga puluhan ribu rupiah. Sebenarnya potensi kopi luar biasa besar dan hal itu jarang dipikirkan oleh petani penghasil kopi karena petani kebanyakan hanya berpikir praktis dan jangka pendek.

Peningkatan pengetahuan terkait penghitungan harga jual produk juga diberikan. Pada umunya perhitungan harga jual harus memperhatikan biaya-biaya yang dikeluarkan dalam pengolahan produk. Biaya-biaya tersebut termasuk biaya biaya bahan baku, biaya pengolahan, biaya pengemasan dan biaya tenaga kerja. Juga diperhitungkan biaya promosi apabila ada juga dimasukkan dalam komponen harga jual. Setelah itu baru ditentukan harga jual kopi setelah ditambah keuntungan atau profit yang diinginkan. Cara perhitungan harga jual yang diberikan relatif sederhana sehingga bisa dipahami oleh petani kopi yang ikut sebagai peserta rekayasa sosial.

Selain itu juga diberikan pengetahuan tentang organisasi koperasi dalam lembaga masyarakat desa hutan. Koperasi Masyarakat Desa Hutan (KMDH) diharapkan dapat menjadi unit produksi untuk memproduksi kopi sangrai maupun kopi bubuk dalam lembaga masyarakat desa hutan. Pengetahuan tentang koperasi meliputi organisasi koperasi dan permodalan koperasi. Agar koperasi dapat menjalankan usahanya koperasi harus memiliki modal sendiri berupa simpanan pokok dan simpanan pokok yang harus dibayarkan oleh anggota koperasi.

\section{Rekayasa Ekonomi}

Menurut hasil perencanaan partisipatif dalam pengembangan kopi arabika specialty ketinggian sedang berbasis kawasan untuk mendukung kemampuan secara finansial atau secara ekonominya diharapkan dapat mengakses permodalan dari lembaga perbankan serta dana CSR (Corporate Social Responsibility) dari Perum Perhutani. Tetapi saat ini petani kopi yang tergabung dalam Lembaga Masyarakat Desa Taman Putri maupun Lembaga Masyarakat Desa Sumberkembang belum mampu menjalin kerjasama secara kelembagaan. Akses modal sebagian besar petani arabika masih diperoleh dari Koperasi Petani Indokom. Sedangkan dana CSR dari Perum Perhutani belum diakses karena Lembaga Masyarakat Desa Hutan belum mampu mengidentifikasi kebutuhan dalam Rancangan Anggaran dan Biaya dalam agroindustri pengolahan sekunder (sangrai 
dan bubuk) kopi arabika. Disamping itu lembaga tersebut masih memiliki keterbatasan sumberdaya manusia baik pengurus maupun anggota dalam pengelolaannya.

\section{Rekayasa Teknologi}

Rekayasa Teknologi dilakukan terhadap pengurus dan anggota Lembaga Masyarakat Desa Hutan Taman Putri dan Lembaga Masyarakat Desa Hutan Sumber Kembang. Tujuan dari rekayasa teknologi ini adalah untuk memberikan pengetahuan terhadap LMDH untuk melakukan penngolahan kopi baik primer (dari olah kering ke olah basah) maupun pengolahan kopi sekunder (pengolahan kopi sangrai dan kopi bubuk). Tidak semua anggota LMDH mendapatkan pelatihan karena diharapkan peserta pelatihan dapat menularkan hasil pelatihan kepada anggota yang lain. Pelatihan diberikan oleh tenaga ahli dari Pusat Penelitian Kopi dan Kakao Jember.

\section{Rekayasa Nilai Tambah}

Tujuan utama dari pelatihan pengolahan primer dan pengolahan sekunder yang diberikan kepada petani adalah untuk memberikan nilai tambah (added value) kepada komoditas kopi terutama kopi arabika ketinggian sedang di Kabupaten Jember. Harga kopi yang diolah secara kering (konvensional) berbeda sebesar Rp. 500,dibandingan diolah secara basah. Pengolahan kopi secara basah memberikan citarasa kopi yang lebih baik dibandingkan diolah secara kering (konvensional). Sedangkan pengolahan sekunder akan memberikan penghasilan yang lebih besar dan kontinyu dibandingkan hanya dijual dalam bentuk gelondong maupun dalam bentuk ose. Sebagai perbandingan kopi arabika ose di tingkat petani dijual seharga Rp. 40.000,sedangkan di Supermarket harga kopi bubuk arabika 200 gram dibandrol seharga 35.000,-. Menurut pihak Pusat Penelitian Kopi dan Kakao untuk kemasan ekonomis kopi arabika umumnya dikemas sebanyak 150 gram dengan harga Rp. 25.000,-. Harga tersebut sudah termasuk biaya bahan baku, tenaga kerja dan pengemasan.

Hasil dari Uji testcup kopi arabika Lembaga Masyarakat Desa Hutan Taman Putri adalah sebagai berikut (secara lengkap hasil testcup di lampiran):

Tabel 3. Hasil Uji Testcup Kopi arabika Lembaga Masyarakat Desa Hutan Taman Putri Desa Kemiri Kecamatan Panti Kabupaten Jember

\begin{tabular}{llll}
\hline \multicolumn{1}{c}{$\begin{array}{c}\text { Karakteristik } \\
\text { (Characteristic) }\end{array}$} & $\begin{array}{c}\text { Skor Citarasa }(\text { Cup } \\
\text { testing Score) }\end{array}$ & $\begin{array}{c}\text { Karakteristik } \\
\text { (Characteristic) })\end{array}$ & $\begin{array}{c}\text { Skor Citarasa }(\text { Cup } \\
\text { testing Score) }\end{array}$ \\
\hline Fragrance/aroma & 7.75 & Balance & 7.125 \\
Flavor & 6.875 & Clean Cup & 10.00 \\
Aftertaste & 6.875 & Sweetness & 10.00 \\
Acidity & 7.50 & Overall & 6.675 \\
Body & 7.50 & Taint/Defect: & -20 \\
Uniformity & 10.00 & Final Score** & 60.50 \\
\hline
\end{tabular}

Comments: Caramelly, woody, astringent aftertaste

* Keterangan skore (Score notation)
6.00-6.75= Good
7.00-7.75=very good
8.00-8.75=Excellent
9.00-9.75=Outstanding

**Final Score notation: Nilai minimum (Minimum Value for) Specilaty Grade $=80$ 
Berdasarkan hasil uji testcup diatas, final score kopi arabika ketinggian sedang dari Lembaga Masyarakat Desa Hutan Taman Putri Desa Kemiri Kecamatan Panti adalah sebesar 60.50 sedangkan untuk memenuhi nilai minimum kualitas kopi arabika specialty adalah 80.00 . beberapa hal yang perlu mendapatkan perhatian dari semua pihak terutama petani kopi LMDH Taman Putri adalah: 1) kualitas buah kopi harus diusahakan merah minimal sebesar 90\%; 2). Dilakukan

sortir terhadap buah kopi yang berwarna hijau, hijau kekuningan dan kuning; serta buah kopi yang kering dan busuk; 3) Buah kopi harus segar tidak boleh menginap; 4) perlu dilaksanakannya pengolahan basah sesuai SOP Puslitkoka. Pelaksaanaan kedua hal diatas sangat mempengaruhi kualitas kopi arabika sehingga dapat mencapai grade specialty seperti yang diharapkan. Tercapainya kualitas pecialty akan mempengaruhi pemasaran dan harga dari kopi arabika ketinggian sedang di Kabupaten Jember.

Hasil uji testcup olah basah dari kelompok Lembaga Masyarakat Desa Sumber Kembang Desa Karangpring Kecamatan Sukorambi adalah sebagai berikut:

Tabel 4. Hasil Uji Testcup Kopi arabika Lembaga Masyarakat Hutan Sumber Kembang Desa Kecamatan Sukorambi Kabupaten Jember

\begin{tabular}{llll}
\hline $\begin{array}{c}\text { Karakteristik } \\
\text { (Characteristic) }\end{array}$ & $\begin{array}{c}\text { Skor Citarasa }(\text { Cup } \\
\text { testing Score) }\end{array}$ & $\begin{array}{c}\text { Karakteristik } \\
(\text { Characteristic })\end{array}$ & $\begin{array}{c}\text { Skor Citarasa }(\text { Cup } \\
\text { testing Score) }\end{array}$ \\
\hline Fragrance/aroma & 7.50 & Uniform Cups & 10.00 \\
Flavor & 7.50 & Balance & 7.25 \\
Aftertaste & 7.50 & Clean Cup & 10.00 \\
Salt/Acid & 7.00 & Overall & 7.25 \\
Bitter/sweet & 7.125 & Taint-Faults: & None \\
Mouthfeel/Body & 7.375 & Final Score & 78.50 \\
\hline
\end{tabular}

Notes : Spicy, nutty

*Keterangan skore (Score notation)

$\begin{array}{ll}\text { 6.00-6.75= Good } & 7.00-7.75=\text { very good } \\ 8.00-8.75=\text { Excellent } & 9.00-9.75=\text { Outstanding }\end{array}$

**Final Score notation: Nilai minimum (Minimum Value for) Specilaty Grade $=80$

Hasil dari uji testcup kopi arabika di Desa Karangpring Kecamatan Sukorambi Kabupaten Jember adalah sebesar 78.50 . Dengan nilai tersebut hanya kurang 1.50 sudah bisa mencapai skala minimum kualitas specialty. hal ini dapat dipahami karena pada saat pelatihan pengolahan kopi primer (olah basah) Lembaga Masyarakat Desa Hutan Sumber Kembang telah menggunakan bahan baku buah kopi merah sebesar $80 \%$ yang memang lebih baik daripada bahan baku kopi arabika dari LMDH Taman Putri. Disamping itu karena pengolahan pagi bahan baku berasal dari hasil panen sore hari sebelumnya sehingga kondisi buah tidak segar.

Dari hasil uji tetscup baik dari LMDH Taman Putri maupun LMDH Sumber Kembang dapat disimpulkan bahwa kopi arabika di Kabupaten Jember sangat berpotensi untuk mendapatkan kualitas specialty asalkan memenuhi persyaratan bahan baku dan diolah secara basah dengan SOP dari Puslitkoka. 
Monitoring dan Evaluasi Pelaksanaan Rekayasa dalam Pengembangan Kopi Arabika Specialty Ketinggian Sedang di Kabupaten Jember

Rekayasa sosial yang telah dilakukan mempu membuat perubahan pada LMDH Taman Putri. Pada tanggal 7 Nopember lembaga tersebut mampu membentuk kepengurusan baru pada Koperasi Masyarakat Desa Hutan (KMDH) Taman Putri. Lembaga koperasi tersebut diharapkan mampu menjadi unit ekonomi produktif bagi anggota masyarakat desa hutan terutama dalam mengembangkan kopi arabika ketinggian sedang di Kabupaten Jember.

Rekayasa ekonomi yang belum dapat dilakukan secara optimal. Menurut hasil perencanaan secara partisipatif lembaga masyarakat desa hutan akan mampu menjalin kerjasama secara kelembagaan dengan perbankan dalam memenuhi kebutuhan operasional usahataninya tetapi belum terlaksana. Petani yang membangun jejaring dengan lembaga perbankan masih sebatas individual. Kebutuhan modal usahatani kopi arabika untuk saat ini masih diperoleh dari Koperasi Petani Indokom.

Dalam rekayasa teknologi, sebenarnya petani mengetahui bahwa dengan menjual dalam bentuk sekunder (sangrai maupun bubuk) akan dapat meningkatkan dan menjamin kontinyuitas dalam pendapatan mereka tetapi mereka selalu takut akan resiko. Lebih mudah menjual dalam bentuk gelondong maupun dalam bentuk ose daripada harus melakukan pengolahan lebih dulu. Jadi bagi petani dirasa lebih sederhana dan cepat menghasilkan tanpa harus dengan memberikan nilai tambah terhadap kopi arabika.

Rekayasa sosial, teknologi dan nilai tambah telah dilaksanakan selama jangka waktu peneletian tetapi perlu disadari bahwa proses untuk merubah mindset petani tidak semudah membalik telapak tangan. Kendala yang paling besar adalah upaya untuk memberikan pemahaman bahwa pengolahan dalam bentuk sekunder akan dapat meningkatkan pendapatan petani terutama apabila tidak hanya sekedar untuk memenuhi kebutuhan subsitensi tetapi lebih untuk kegiatan komersil (dipasarkan). Menurut Nasdian (2014:98) bahwa untuk menjalankan partisipasi secara terus menerus, dalam pengambilan keputusan dan pembentukan struktur komunitas memerlukan suatu kegiatan yang terus menerus. Disamping itu memang perlu dirubah terkait asumsi tentang masyarakat itu sendiri. Bahwa dalam proses pembangunan alternatif (pemberdayaan) yaitu: 1) masyarakat memiliki kemam-puan yang tersedia perlu dioptimalkan agar mereka berkembang sesuai dengan pengetahuan mereka; 2) pengetahuan lokal (local Knowledge) dan teknologi tepat guna sebagai basis pengembangan-nya (Zubaedi, 2013: 146).

Memang sulit untuk mencapai partisipasi murni dan mengembangkan tingkat partisipasi dalam komunitas. Menurut Nasdian (2014: 100-101) bahwa komunitas akan berpartisipasi apabila kondisikondisinya kondusif untuk melakukan kegiatan tersebut yaitu:

1) Kalau mereka memandang bahwa kegiatan tersebut merupakan isue yang penting bagi mereka. Jadi yang menentukan bahwa isue itu penting atau tidak adalah komunitas sendiri bukan orang luar. Biasanya isue-isue itu menyentuh kebutuhan prioritas komunitas dan menjawab kebutuhan dasarnya, npeningkatan pendapatan,kesehatan dan lain-lain;

2) Mereka akan berpartisipasi apabila mereka merasa bahwa tindaknnya akan membawa perubahan khususnya pada tingkat rumah tangga atau individu, kelompok atau komunitas.

3) Harus ada pengakuan dan penghargaan akan bentuk-bentuk partisipasi. Pengakuan dan penghargaan tidak hanya sebatas pada kegiatan formal tetapi juga 
pada kegiatan non formal sesuai dengan keragaman ketrampilan, bakat dan minat dari warga komunitas;

4) Harus dipertimbangkan dukungan ketersediaan transportasi, keamanan, waktu, dan lokasi aktivitas serta lingkungan dalam kegiatan partisipasi;

5) Struktur dan proses partisipasi memerlukan metode-metode yang partisipatif pula sehingga tidak menyingkirkan orang-orang tertentu yang memiliki keterbatasan komunikasi seperti cenderung pendiam, kurang percaya diri, tidak ingin menginterupsi orang lain dan tidak memiliki kemampuan verbal.

\section{KESIMPULAN}

1. Penyusunan model partisipatif bersama masyarakat desa hutandengan pendekatan Participatory Research Appraisal untuk pengembangan kopi arabika specialty ketinggian sedang berbasis kawasan di Kabupaten Jember mengikuti metodemetode yang lazim dimanfaatkan dalam Participatory Research Appraisal (Chambers 1996).

2. Pelaksanaan Kegiatan Partisipatif Pengembangan Kopi Arabika Specialty Ketinggian Sedang Berbasis Kawasan di Kabupaten Jember adalah : i) Rekayasa sosial terhadap pengurus dan anggota Lembaga Masyarakat Desa Hutan. Rekayasa sosial tersebut dimaksudkan untuk meningkatkan kapasitas pengurus dan anggota Lembaga Masyarakat Desa Hutan Taman Putri dan Lembaga Masyarakat Desa Hutan Sumber Kembang dalam pengembangan kopi arabika specialty ketinggian sedang di Kabupaten Jember, ii) Rekayasa ekonomi dengan meningkatkan akses permodalan terhadap perbankan dan dana SCR dari Perum Perhutani belum berjalan optimal, iii) Rekayasa Teknologidilaksanakan terhadap pengurus dan anggota Lembaga Masyarakat Desa Hutan Taman Putri dan Lembaga Masyarakat Desa Hutan Sumber
Kembang. Tujuan dari rekayasa teknologi ini adalah untuk memberikan pengetahuan terhadap LMDH untuk melakukan penngolahan kopi baik primer (dari olah kering ke olah basah) maupun pengolahan kopi sekunder (pengolahan kopi sangrai dan kopi bubuk), iv) Rekayasa Nilai Tambahadalah untuk memberikan nilai tambah (added value) kepada komoditas kopi terutama kopi arabika ketinggian sedang di Kabupaten Jember.Berdasarkan hasil uji testcup diatas, final score kopi arabika ketinggian sedang dari Lembaga Masyarakat Desa Hutan Taman Putri Desa Kemiri Kecamatan Panti adalah sebesar 60.50. Hasil dari uji testcup kopi arabika di Desa Karangpring Kecamatan Sukorambi Kabupaten Jember adalah sebesar 78.50.Dari hasil uji tetscup baik dari LMDH Taman Putri maupun LMDH Sumber Kembang dapat disimpulkan bahwa kopi arabika di Kabupaten Jember sangat berpotensi untuk mendapatkan kualitas specialty asalkan memenuhi persyaratan bahan baku dan diolah secara basah dengan SOP dari Puslitkoka.

3. Berdasarkan kegiatan monitoring dan evaluasi bahwa kegiatan penelitian dengan menggunakan PRA (Participatory Research Appraisal) dalam pengembangan kopi arabika specialty ketinggian sedang berbasis kawasan di Kabupaten Jember memerlukan upaya yang terus-menerus dengan melibatkan partisipasi aktif masyarakat desa hutan yang benar-benar-benar ingin melakukan perubahan dalam menjawab kebutuhan utamanya untuk meningkatkan pendapatannya serta dukungan dari berbagai pihak yang secara sinergis untuk mendukung aktifitas dalam melakukan pengolahan primer maupun pengolahan sekunder. 


\section{DAFTAR PUSTAKA}

Adimihardja, Kusnaka. 2003. Participatory Research Appraisal. Bandung: Humaniora.

Bungin,B. 2010. Metodologi Penelitian Kualitatif Aktualisasi Metodologis ke Arah Ragam Varian Kontemporer. Jakarta: Rajawali Pers.

Chambers, Robert. 1996. PRA: Memahami Desa Secara Partisipatif. Yogyakarta: Kanisius \& Oxfam.

Nazir, M. 2003. Metode Penelitian. Jakarta: Ghalia Indonesia.

Siahaan, Jimmy Andar. 2008. Analisis Daya Saing Komoditas Kopi Arabika Indonesia di Pasar Internasional. Skripsi. Institut Pertanian Bogor. Tidak Dipublikasikan
Suharto, Edi. 1997. Pembangunan, Kebijakan Sosial dan Pekerjaan Sosial: Spektrum Pemikiran. Lembaga Studi Pembangunan STKS (LSP-STKS). Bandung

Nasdian, Fredian Tonny. 2014. Pengembangan Masyarakat. Kerjasama antara Departemen Sains Komunikasi dan Pengembangan Masyarakat Fakultas Ekologi Manusia IPB dengan Yayasan Pustaka Obor Indonesia.Jakarta

Zubaedi.2013.Pengembangan Masyarakat Wacana dan Praktek. Jakarta: Kencana Prenada Media Group. 